\title{
Voz de tierra que llama: o cuando el repertorio re-territorializa
}

\section{Jorge Luis Yangali Vargas}

Dos son las principales compañías teatrales surgidas en las décadas finales del siglo XX en el centro del Perú - Barricada Teatro y Grupo de Teatro Expresión-, la primera dirigida por Eduardo Valentín Muñoz y la segunda por María Teresa Zúñiga Norero. Barricada Teatro surge en 1976 durante el gobierno militar de tendencia izquierdista, y diez años después se funda Expresión durante el primer gobierno aprista. ${ }^{1}$ Ambas agrupaciones se sumarán a muchas otras compañías teatrales peruanas vinculadas al Movimiento de Teatro Independiente (MOTIN), el que desde 1974 impulsaban Leoncio Bueno, Jorge Guerra, Wolfgang Luchting, Ernesto Ráez y Sara Joffré.

El MOTIN, como lo denomina Sara Joffré (El libro de la Muestra $10),{ }^{2}$ quiso responder a la interrogante iexiste el teatro peruano?, pregunta que funda e identifica el MOTIN y que impone en las diversas actividades del movimiento (talleres, conversatorios, mesas de críticos y, principalmente, las muestras de teatro) ${ }^{3}$ tomar en cuenta, preferentemente, piezas de agrupaciones o autores peruanos. De este modo, la interrogante constituyó tanto un estímulo como un reto, no sólo para las emergentes compañías teatrales junto a sus directores y dramaturgos (muchos de ellos efímeros y otros, como los dos que venimos reseñando, de largo aliento y alcance) sino y sobre todo quizá para los que tienen que ver con la calidad, la pertinencia y el juicio sumario de dichas propuestas: los críticos y estudiosos del arte teatral.

La intención de montar y discutir piezas teatrales de autores peruanos fue complicada porque se descubrió un abanico de propuestas que procedían desde territorios amazónicos, tanto de sierra como de costa y desde las voces amazónicas, quechuas, aimara, etcétera. Al abrirse lo peruano, ya no debía entenderse sólo desde una mirada homogénea y monoglósica, sino desde enfoques heterogéneos (Cornejo 21) y heteroglósicos (Ballón 119), hablándose de éste modo no de un teatro peruano, sino de teatro peruano(s). ${ }^{4}$ Tanto 
Barricada como Expresión, cada grupo en su peculiar modo de entender los lenguajes escénicos, vienen respondiendo a este interrogante, año a año, montaje a montaje.

De las cuatro décadas de trabajo escénico impulsadas por el MOTIN, nos interesan en el presente estudio las intermedias, aquellas que convergen con el tiempo que el sociólogo Nelson Manrique (2002) calificara como el "tiempo del miedo", las que se asentaron en el mayor escenario traumático que tuvo el Perú de fines del siglo XX. Esta década, según la Comisión de la Verdad y Reconciliación Nacional (CVR) en su Informe final (2003), tuvo un costo en vidas humanas, entre muertos y desaparecidos, de aproximadamente 70 mil personas, así como de unas 120 mil familias desplazadas de su zona de origen debido a la violencia política, lo que podría representar el éxodo de más de 600 mil personas 5 .

Son desplazados cuya problemática, con el paso del tiempo, se ha ido desplazando y desligando por lo conflictivo e irresoluble de las agendas política y jurídica, ${ }^{6}$ mas no de la memoria colectiva, memoria que ha tenido en diversas áreas, como la artesanía y el arte, a sus mejores aliados contra el olvido. Y de entre las expresiones artísticas, en general las artes escénicas, en el ámbito peruano de fines del siglo XX, han venido asumiendo el enorme rol de forjar un valioso archivo estético que ha ido dando cuenta del pasado, ya sea sosteniendo y complementado la narrativa histórica, ya sea disidiendo de los discursos oficiales.

Para una sociedad como la peruana, que a lo largo de su historia republicana ha elaborado, establecido, reservado y estudiado su archivo homogenizante desde y en el centro territorial del poder — Lima-, el surgimiento de archivos alternos al centro del poder ha significado hacer visible lo invisible: una sociedad heterogénea - un mundo ancho y ajeno, nos diría el escritor indigenista Ciro Alegría-, en la que sus intelectuales y entre ellos sus artistas de provincia, como lo son Eduardo Valentín Muñoz y María Teresa Zúñiga Norero, además de los retazos de archivo que han heredado del archivo central, cuentan con un repertorio de documentos vivos con los cuales se han sumado a la tarea de forjar el Arkhé teatral de lo(s) peruano(s).

En Mal de archivo (1997), Jacques Derrida realiza un estudio etimológico del vocablo "archivo" y precisa su procedencia como raíz griega arkhé - término que, de acuerdo a Derrida permite coordinar dos principios, uno ontológico y el otro nomológico. El primero, asociado tanto a la naturaleza como la historia, refiere un "allí donde las cosas comienzan" (14) y el otro, que tiene que ver con la ley, nos habla de un "allí donde los hombres y los 
dioses mandan, allí donde se ejerce la autoridad, el orden social, en ese lugar desde el cual el orden es dado" (14). En estos dos sentidos del término, nos atrevemos a afirmar que los teatros de lo(s) peruano(s) comienzan ontológica y nomológicamente con el MOTIN. Y si hablamos de manera particular del arkhé teatral de la sierra central peruana, se inician con los trabajos de María Teresa Zúñiga Norero y Eduardo Valentín Muñoz.

De entre el archivo que contiene la producción teatral de estos dos autores, para el presente estudio hemos decidido extraer para su análisis el archivo textual Voz de tierra que llama ${ }^{7}$ de Eduardo Valentín Muñoz, unipersonal estrenado en la Muestra de Teatro de 1992. ${ }^{8}$ Decisión que tiene que ver con el énfasis de la propuesta dramatúrgica de Valentín Muñoz en la revisión de la historia y la construcción de la memoria. Y de manera especial aquella memoria que tiene que ver con la violencia política peruana, la que se puede ver en la tetralogía de la cual Voz de tierra que llama forma parte: El Tuerto (1985), La Mamacha de Las Mercedes (1990), Voz de tierra que llama (199295) y Cáceres, el estigma de la guerra (2001). De ellas, La Mamacha de las Mercedes y Voz de tierra que llama tratan de la problemática de las familias desplazadas. Respecto a la temática del retorno de los desplazados, en la historiografía del teatro peruano hallamos que un primer intento de aproximación al tema desde el teatro fue el trabajo realizado por el grupo Yuyachkani en Contraelviento (1989), obra en la que Guaco y Colla, personajes míticos femeninos, recorren los solitarios caminos andinos y comprueban que los pueblos están despoblados y las tierras sin cultivar, vacío que se debe a la violencia y al éxodo de la población del campo hacia las ciudades (Villagómez). En 1996, Yuyachkani retoma el tema de los desplazados en Retorno, en la que se muestran las secuelas de la guerra: desorientación, aldeas destruidas y tierras de cosecha quemadas. Como explica Diana Taylor, "There is no going forward, no going back, no home to return to" (202). Yuyachkani estaría de este modo clausurando todo tipo de esperanza de reterritorializar las poblaciones andinas. Según Taylor, estaría negando a los desplazados el derecho de retorno. No obstante, creemos que la propuesta de Yuyachkani más bien estaría negociando con el Estado las condiciones de retorno hacia una tierra devastada a cambio de inversión que permita el desarrollo luego de la asolación.

Igual de negociadora es la propuesta de Eduardo Valentín, quien en 1990 con Mamacha de las Mercedes cuestionaba la política de retorno que el primer gobierno fujimorista planteó para que los desplazados regresaran a sus lugares de origen. Según Villagómez, en Mamacha de las Mercedes se 
antepone a la propuesta estatal centralista, racista y excluyente un proyecto que tiene que ver con la visión ritual, telúrica y religiosa del mundo del hombre andino.

Voz de tierra que llama se añade a este corpus o archivo teatral sobre el desplazado, continuando con la negociación. La obra se divide en dos partes. En la primera se oyen ocho voces numeradas que corresponden a ocho poemas que la actriz declama, intercalándolos con la interpretación de cuatro cantos (huaynos-mulizas). A través de este conjunto de textos los espectadores nos informamos del desplazamiento del campo a la ciudad que sufrieron estas voces, del sufrimiento que les causa el no poder territorializarse en la ciudad y de la añoranza de volver y re-territorializar el campo. Es la última voz la que decide retornar a sus tierras. Mujer desanda este retorno en el segundo acto, encontrándose en el camino hacia su reimplantación con la Mamapacha con otros seres: dos fantasmales (Wawacha y Mamacha) y uno divino (Wamani).

Le atribuimos la naturaleza de archivo a la obra Voz de tierra que llama por su condición material, textual. No obstante tenemos presentes los momentos "vivos", aunque efímeros, como lo diría Diana Taylor en alusión al "repertorio". Cabe precisarse que Taylor atribuye al archivo la condición de permanente por el material que lo conserva (documentos, vídeos, huesos, etc.), mientras que el repertorio, en oposición y complementariedad al archivo, está definido por lo efímero y asociado al momento de producción y reproducción de conocimiento o transmisión de memoria a través de los gestos, la voz, la danza, etc.

Sin embargo, la paradoja del "repertorio" es la de no poder ser capturado o retenido por los mecanismos del archivo para poder ser retransmitidos. Taylor ejemplifica esta paradoja del siguiente modo: "A video of a performance is not a performance, though it often comes to replace the performance as a thing in itself (the video is part of the archive; what it represents is part of the repertoire)" (20). Esta misma paradoja se resuelve al tener en cuenta el carácter vivo y presente del repertorio, el que le permite ser registrado y retransmitido en la memoria tanto individual como colectiva:

Performances also replicate themselves through their own structures and codes. This means that the repertoire, like the archive, is mediated. The process of selection, memorization or internalization, and transmission takes place within (and in turn helps constitute) specific systems of re-presentation. (20) 
Dentro de estos y los siguientes parámetros históricos y teóricos, nos preguntamos por aquel específico sistema de representación sobre el cual Eduardo Valentín ha trabajado tanto en la construcción del archivo como en la expresión de su repertorio en Voz de tierra que llama. Como dijimos, las ocho voces de la primera parte de la obra nos dan a entrever a unos sujetos andinos encerrados en su nostálgica mirada al pasado, una mirada que les impide adoptar y adaptarse en traumáticos procesos de transformación social, cultural y económica, y una mirada que les impide territorializarse fuera de su territorio, luego de haber sido desterritorializados.

Según Rogério Haesbaert, en las discusiones actuales sobre el concepto de territorio hay tres definiciones. La primera lo describe como un "área de formas o, por lo menos, de relaciones de poder relativamente homogéneas" (67), definición que nos permite hablar de los procesos de territorialización y desterritorialización como procesos asociados al "control del acceso" (66) a dichas áreas. La segunda definición es la de "territorio en tanto red centrado en el movimiento y conexión" (66) y la que nos permite hablar del proceso de reterritorialización. Finalmente, la tercera definición trabaja la idea de territorio como híbrido (66), tanto entre el mundo material como el ideal, entre la naturaleza y la sociedad en sus esferas económicas, políticas y culturales, definición que nos permite comprender el proceso de multiterritorialidad. Haesbaert señala este último atributo como privativo de quienes se desplazan con fines turísticos o de negocios.

Ampliando las definiciones de Haesbaert, hallamos que el proceso de territorialización tiene que ver con la "interacción entre las relaciones sociales y el control del o por el espacio" (194). Un buen ejemplo de este proceso sería la organización de los desplazados durante el periodo de violencia para invadir y fundar enormes asentamientos humanos en las zonas periféricas a las grandes ciudades, proceso al que se alude en la primera parte de $\mathrm{Voz}$ de tierra que llama a través de los vocablos "arena", "bandera" y "cemento". Esta territorialización, para el caso peruano, fue inicialmente denominada como "invasión" por la forma en la que los desplazados se hicieron de estos espacios, para luego llamarse "asentamiento humano" o "comunidad urbana", siendo la mayor de ellas la de Villa el Salvador, en Lima, que constituyó un ejemplo exitoso de comunidad autogestionaria de los desplazados, a pesar de su heterogénea población. Ejemplos como el de Villa el Salvador dan cuenta de desplazados que supieron territorializarse en la "arena".

Sobre el proceso contrario a la territorialización, Haesbaert habla del proceso de desterritorialización, valiéndose de dos sujetos aludidos por 
Deleuze y Guattari: el migrante y el nómada. Los filósofos franceses destacan la figura del nómada que se resiste a toda fijación y a todo comportamiento socialmente codificado (Haesbaert 198). Teniendo en cuenta que el proceso desterritorializador se complementa con el proceso territorializador, el ejemplo anterior que nos proporciona Voz de tierra que llama nos sigue sirviendo. No obstante, nos señala una diferencia. En este proceso el sujeto andino de Voz no logra reterritorializarse, teniendo la urgencia de volver a su tierra de origen. En tal sentido, el viaje que realiza la Mujer del segundo acto de la obra traza el siguiente proceso: se desterritorializa de donde no se territorializó, para re-territorializarse en el espacio de donde la desterritorializaron. Para ampliar sobre el sentido y dirección de este complejo proceso en la obra, conozcámosla más.

Las ocho voces, notorias en el "archivo" por los números que dividen sus parlamentos poéticos, fueron agrupadas bajo el subtítulo de "Espejismos de arena y bandera". Estas voces son complejas de representarse en el performance debido al carácter unipersonal de la obra. Esta misma complejidad enriquece al personaje escénico, pues lo hace portavoz y representante de las voces-número (formalmente de los versos y estrofas), cuyas nostalgias no tienen otro medio de expresión más que la efímera voz de este personaje que durante la ejecución del repertorio, es la actriz que escénicamente parecería dialogar consigo misma, pero que en razón al "archivo", es decir al texto fijado por el dramaturgo, dialoga con las otras voces que la ocupan, que se encarnan en ella.

La primera voz alude a "vientos ajenos/negros y traidores" (Voz 29) que la empujaron hasta unas "pampas/donde el sol se tragó toda el agua". Mientras tanto la cuarta voz, que también fue llevada por el "viento", se queja ante la ausente Mamapacha de estar habitando en un "aquí" que no describe ni nombra (29).

La segunda voz dice conocer la muerte, conocer "su voz de candela/ reventando en los pechos" (29) de muchachos y muchachas. La quinta voz también deja entrever que conoció a la muerte de cuyo "vientre" escapó "apenas abrió la boca" (30). Esta quinta voz añade haber escapado "para no ver". ¿Qué es lo que no quiso ver? No lo dice, pero el haber huido en tales circunstancias, quizá por puro instinto de sobrevivencia, le permite justificar su desdichado destino, el que la voz describe como "camino desesperado". La sexta voz tampoco quiso "volver los ojos atrás" (30), pues ella sintió que danzaban juntos la "muerte" y el "viento", el mismo viento que como ya sabemos, empujó a la primera y cuarta voz hasta aquel lugar de desolación. 
Estas voces, al igual que la Mujer de la segunda parte de la obra, asumen la culpa de haber salido escapando de su tierra, siendo los padecimientos en estas tierras extrañas el justo castigo que tienen que pagar por haber huido.

La tercera voz nos describe el arenal sin "vida", "quemante", "castigador", pero añade algo fundamental en su descripción del espacio que habita. Habla de banderas "quemante[s]" "con espinos", "castigadora[s]". El último adjetivo calificativo, "castigador", también es atribuido a "la arena", lo cual le permite fusionarlos para afirmar: "Viento y arena de espejismos rotos/con bandera de sueños" (29).

La séptima voz, más afirmada en la labor agrícola, se resistió al desplazamiento: "Mis pies,/no quisieron caminar, /no quisieron dejar la tierra..." (30). Pero igual escapó de la muerte. El dolor de habitar aquel "cementerio de arenas y cemento/con banderas de sueños" (30) es más hondo debido a esta resistencia. Es un dolor que le hace sentirse prisionera en aquel lugar. Y si bien le salieron alas para dejar su primera tierra, la prisión que ahora habita le ha arrebatado aquellas alas que le permitirían retornar.

El vocablo añadido por esta séptima voz para describir el lugar habitado por las otras voces es "cemento", el que se suma al de "arenas" y "banderas" para ofrecernos los rasgos mínimos para suponer que nos encontramos pisando un infernal barrio joven o asentamiento humano o comunidad urbana. Son nombres con los que, como dijimos, en el Perú refieren a las extensas zonas periféricas de las grandes ciudades, principalmente de la capital, zonas que las oleadas humanas de desplazados arrebataron, ya sea al Estado o a propietarios privados durante el tiempo del miedo y mucho antes. ${ }^{9}$

La cuarta, quinta, sexta y séptima voz, al final de sus lamentos, entonan huaynos-mulizas. Los versos de los huaynos ${ }^{10}$ que ellas cantan están incompletos en el texto/archivo, lo cual nos da la idea de que estas voces sólo poseen fragmentos, fragmentos de memoria que hablan de un archivo fragmentado, el que requiere necesariamente de su repetición, una repetición que no permite que el personaje, la actriz y el auditorio olviden dichos fragmentos.

El lamento de la octava voz es estremecedor: "Aiiiii uuuuu aaaaaiiii" (31). Mientras que las otras voces o bien tienen palabras para describir y localizarse o bien tienen cantos con los cuales consolarse, esta voz no tiene medio de expresión para hacerlo:

Ya no puedo cantar.

Me falta la palabra

en este mundo

que no entiendo. (31) 
Este no entender no sólo tiene que ver consigo mismo, sino también con la naturaleza que la esquiva y de la cual no obtiene respuesta: "El viento no responde, mamapacha/ como antes" (31). La desolación es total para esta octava voz. Ella no puede establecer un lazo afectivo ni con la naturaleza pasada ni con la presente. El único recurso posible de (re)encuentro con su naturaleza misma, su condición telúrica, su propio cuerpo es: "la memoria de mi cuerpo/recuerda el Santiago del Retorno" (31). Afirma y brota en ella el canto corporal, la danza — el Santiago ${ }^{11}$ - que no requiere de la letra de las canciones. Aunque el archivo no esté presente, el canto no requiere de él porque la memoria de su cuerpo está allí en ella, en su repertorio corporal.

Los fragmentos de las canciones, las voces en cada poema numerado, el baile de retorno, el rito del pago a la tierra en el segundo acto, entre otros recursos de los cuales se vale la obra, nos dan la sensación de estarse (re) construyendo la memoria o el pasado, como una especie de collage, cuyos elementos principalmente proporciona el "repertorio". Pero el uso que hace Eduardo Valentín del collage no es irónico como en la estética postmodernista (Hutcheon). Valentín se vale del collage para darle un rasgo real(ista) o material a los dispersos elementos proporcionados por el repertorio, una materialidad que por efímera se halla sólo en las voces de los fantasmas. Su objetivo final es reactualizar y reformular el uso y sentido de los elementos que le proporciona el repertorio oral andino, un repertorio que el moderno sistema de representación rechaza por no responder a los cánones de la letra y la alfabetización.

Tomemos en consideración en la reconstrucción de la memoria el cuestionamiento de las grandes narrativas (o archivos) homogeneizantes, no sólo las mundiales, sino también las nacionales, lo que ha permitido el surgimiento de historias, y con ellas, arckhes en plural. Linda Hutcheon opone a los relatos totalizantes, los que caracterizaron la construcción del discurso histórico en la modernidad, aquellas historias abiertas y fragmentadas, propias de los tiempos postmodernos:

What has surfaced is something different from the unitary, closed, evolutionary narratives of historiography as we have traditionally known it: as we have been seeing in historiographic metafiction as well, we now get the histories (in the plural) of the losers as well as the winners, of the regional (and colonial) as well as the centrist, of the unsung many as well as the much sung few, and I might add, of women as well as men. (66) 
No estamos sugiriendo que los trabajos de Valentín Muñoz deban ser leídos como postmodernos en el sentido lato y empobrecedor del término, ni en el exclusivo sentido que Lyotard propone al hablar de la condición postmoderna, es decir de desconfianza frente a los grandes relatos, sino que los artistas, como el que estamos viendo, han hecho uso de una serie de recursos con los cuales han interpretado desde diferentes perspectivas tanto de los llamados "brute events" (Hutcheon 75) como de las "master narratives" (86), redefiniéndolos, reinterpretándolos, resignificándolos y ampliando los límites de significado de la representación de los hechos del pasado. A fin de cuentas, diríamos que la intencionalidad ha sido la de politizar el uso del "archivo" o más específicamente del arckhe, haciendo de éste un lugar de constante tensión y negociación y no sólo de imposición y sumisión.

Ahondando en esta negociación, analizamos la segunda parte de la obra, la que da cuenta del viaje de retorno de Mujer. Al final de la primera parte, la octava voz es sobrecogida apoteósicamente por la memoria de su cuerpo que la hace recordar el "Santiago del retorno". Es una memoria que si bien la mantiene en el anonimato, le atribuye un rasgo identitario de su género: el de "Mujer". En su viaje Ella se encuentra con tres personajes: Wawacha, Mamacha y Wamani. El encuentro de Mujer con Wawacha lleva el subtítulo "El retorno: desenterrando la vida". Este desentierro nos permite entrever en Wawacha un aura fantasmático. Wawacha sufre aún los dolores del torturado, a quien "No dejaron vivir.../ni morir" (32). Representa al niñofruto que fue arrancado del vientre de la tierra antes de nacer, el que no tiene más esperanza que echar raíces nuevamente en el vientre de la Mujer y en los sueños de ella. Es por ello que le pide a Mujer que lo lleve a él también en su viaje de retorno. Ella inicialmente se niega porque no tiene la certeza de llegar, como tampoco tiene la certeza de saber el lugar donde deba dejar a Wawacha. No tiene la certeza de llegar porque "ya no pued[e] respirar en las alturas/El cansancio [...] pesa como piedra" (32), así dándonos a entender que su cuerpo está reaprendiendo a reconocer la geografía, el territorio físico del cual fue desterritorializada. Y para reaprender tiene que volver por el mismo sendero recorrido, sendero en el que se encontró con Wawacha.

Ante la inicial negativa de la Mujer, Wawacha le reprocha el haber pasado por donde él se encontraba, despertándole la esperanza de retorno. Le increpa el que no haya elegido otro camino en su viaje de regreso: "¿por qué vienes a recoger tus pasos y tus recuerdos?" (32). Con esta pregunta y reproche Wawacha está cuestionando el propósito mismo del viaje de retorno, para que éste no sea un suceso melancólico más. Porque un viaje por la ruta 
de la melancolía irresoluble y sin compromiso social no tiene más sentido que el de incrementar el dolor y la melancolía misma. De ahí que la propuesta de Wawacha y de la obra en general sea la de un retorno que desentierre la vida allí donde pasó la muerte. Que no desentierre el pasado para buscar detenerse en las razones del enterramiento, sino para reavivar los afectos, además de volver a sembrar en aquella tierra desenterrada una semilla, una esperanza, una utopía. Es un retorno no para buscar olvidar las causas de la desterritorialización, sino para re-territorializar lo desterritorializado. De este modo, Valentín estaría abrazando la utopía milenarista de la cual nos habla la historia y antropología andina: el retorno de los vencidos al poder del cual fueron desterritorializados. ${ }^{12}$

Para Eduardo Valentín el retorno no es para olvidar lo pasado, sino para aprender a vivir con una utopía. Por eso Mujer recorre los mismos lugares que recorrió durante su huida, durante su éxodo. Wawacha finalmente le dirá a Mujer, "no puedes olvidar, mamay/¡no debes!” (33). Con tales parlamentos, Wawacha es el pasado violentado, el pasado trunco, pero también es el mañana, la semilla utópica que la Mujer finalmente decide llevar consigo: "palomita mariposa.../aquí está mi vientre/acomódate torcacita/vuela conmigo. ¡vamos!" (33). Y continúa su viaje.

En este viaje ascendente Mujer tiene un segundo encuentro, con Mamacha, el fantasma de una mujer que en tierra ajena no puede descansar. Mamacha es una condenada. ${ }^{13} \mathrm{El}$ "Condenado" es un personaje andino cuya muerte no ha sido natural, por lo que purga entre dos mundos y reclama una víctima o en su defecto un rito de duelo. Las causas de su condena son muchas. Los más comunes relatos del folklore andino hablan de condenados por haber muerto en estado incestuoso, haberse suicidado, haber sufrido un accidente o haber sido asesinado con mucha violencia. Los dos últimos casos son importantes porque tienen que ver con la desterritorialización del cuerpo de la víctima; más aun si éste ha sido desmembrado, lo que ocasiona que su alma pene, buscando remembrarse y reterritorializarse.

Mamacha relata que fue objeto de un asesinato colectivo, efectuado por "los que caminan de noche" (33), y que su cuerpo junto a los de los otros cadáveres, fue arrojado a "esta quebrada/ que no conozco" (33). Al conocer la razón de la pena de Mamacha, Mujer promete traerle "en todos los santos/ agüita bendita te traeré para tu sed" (34), promesa que si bien pudiera aliviar, no restituye ni elimina el estado de condenación de Mamacha. Por lo tanto ésta le suplica que la lleve "hasta el valle del Canipaco,/llévame,/ 
allí descansaré en paz./En tierra ajena no puedo" (34), pedido que, al igual que le hizo Wawacha, tiene que ver con el compromiso para con el pasado.

Valentín estaría exigiendo no sólo un compromiso para con el desplazado, sino también para con aquellos que están penando, aquellos cuya materialidad no está definida ni ubicable. Estamos hablando de los miles de desaparecidos en cuyas familias el luto no llega y no llega porque no hay cuerpo que velar. Y no hay cuerpo, aunque sea el simbólico, porque en el sistema de información del número de víctimas siempre habrá vacíos. El archivo tiene agujeros.

Mujer decide llevar consigo a la condenada. Pero no la puede llevar como a Wawacha en su vientre. La tiene que llevar al lado suyo confluyéndola en sí misma, en el gesto performático del baile. Por eso le pide a Mamacha, "Baila, bailando, baila, así te llevaré" (34). Como ya sabemos, la obra es un unipersonal, por lo que la propuesta de Valentín, ante el fantasma que nos acosa, es llevarlo, no abandonarlo. En el performance unipersonal de Voz de tierra que llama, el fantasma tiene la cualidad de tomar la forma de la actriz que la contiene. El fantasma es la actriz y ella es el teatro, con lo que Eduardo Valentín estaría caracterizando la función del teatro como aquel arte que tiene la propiedad no sólo de revelarnos al fantasma, sino también de hacer que éste nos acompañe.

Marvin Carlson nos recuerda la "cualidad fantasmal" de las culturas teatrales en general, cualidad que le permite al teatro tener un vínculo complejo en relación a la construcción de la memoria cultural, haciendo del teatro un "repositorio de la memoria cultural" (2). Un repositorio de aquellos episodios o fantasmas que retornan, que reaparecen para ser repetidamente representados.

Luego de asumir el compromiso de no olvidar y llevar consigo los fantasmas del pasado, Mujer se encuentra con Wamani, el dios de la montaña, celoso protector de Mamapacha, la diosa tierra y el último personaje con el que Mujer quiere encontrarse. Pero antes tiene que persuadir a Wamani para que la deje trasuntarlo, siendo él la montaña y dios, dios que le increpa su cobardía y las consecuencias desoladoras de la misma:

Eres cobarde.

Eres traidora

no has amado, no has querido resistir.

Ahora, $[\ldots]$ 
Piedra sobre piedra está el pueblo.

Espinos han crecido

por todas partes. (35)

Ahora le es revelada a través de la voz divina la razón de la extraña culpa que Mujer decía estar pagando, una culpa que deja de ser extraña. La culpa que Wamani visibiliza es la de no haber resistido a la muerte, de haber abandonado la tierra, de haber dejado que la danza macabra se imponga y destruya todo signo de vida humana. Figurando la muerte como danza, se entiende por qué Wamani le pide a la Mujer que baile con él y por qué ella le pidió a Mamacha que baile bien fuerte. El baile no sólo es la memoria corporal que recuerda los caminos andados, sino también es un acto de ofrenda a los dioses, una ofrenda ritual que la Mujer realiza, logrando que Wamani le permita el ingreso a las tierras de la Mamapacha. ${ }^{14}$

La reterritorialización final y el encuentro con la Mamapacha le revelan a Mujer una identidad de la cual no era consciente: estar muerta. El único parlamento que la diosa expresa es semejante al de Wamani. Increpa a Mujer por su abandono y describe las consecuencias del mismo:

En tumba negra grande y solitaria

me han convertido

sembraron mi pecho

con negros espinos

que hoy me duelen tanto,

No puedo, no intentes...

Estás muerta también. (36)

¿Qué es lo que no puede Mamapacha? ¿Qué es lo que le pide que no intente? El archivo no nos lo revela. No lo hace porque el nuevo aprendizaje está fuera del archivo, en el repertorio. Es decir que Mamapacha no puede perdonar el abandono sufrido en tiempos de violencia porque su identidad territorial también ha sido desterritorializada. Y demanda de sujetos vivos que la reterritorialicen, desvalidando de este modo las identidades muertas. Por eso Mujer tiene que afirmarse en su naturaleza viva y la mejor forma de hacerlo es traer consigo su "semillita" y declarar que lo posee, que lo recogió a Wawacha en el camino de retorno. Por ello, luego de ser aceptada su ofrenda y perdonado su abandono, Mujer le pide a la diosa que le deje poner una semilla, como se lee en los siguientes versos:

Déjame poner una semilla

En tu corazón

Juntos, 
Vientre a vientre

¡Venceremos la muerte! (37)

Lo que se podría observar en el performance es un contrato natural entre la Mujer y la diosa tierra, un contrato que tiene que ver con la vida, con la mutua interdependencia entre Tierra y Humanidad. Mujer representa a la humanidad en general y a la población andina en específico. Este contrato se ritualiza en el repertorio andino del "paguito" u ofrenda a la tierra. Es un contrato en el que la voz de la tierra ya no se oye a través de la escritura o el archivo, sino en el repertorio intersubjetivo del sujeto que la representa, que le da voz:

Ahora,

Háblame con la coquita.

Dime mamita, si me aceptas.

GRACIAS MAMAY.

GRACIAS MAMAPACHA. (37)

Podríamos concluir que en Voz de tierra que llama el o la sujeto(a) desplazado(a) ha resistido el trauma que significó su desterritorialización original. Su cuerpo se ha resistido a conservar en su memoria los bailes y cantos de las tierras a las que llegó luego de ser desterritorializado por aquellos "vientos ajenos negros y traidores" (29). Se ha resistido a pactar ("vientre a vientre") con la "arena" y las "banderas", con la otra tierra que le niega la vida. Se ha resistido a territorializarse en el archivo hegemónico para optar por medio de la actualización del repertorio re-territorializar su desterritorialización.

\section{Universidad Iberoamericana}

\section{Notas}

1 La Alianza Popular Revolucionaria Americana (APRA) fue fundada el 7 de mayo de 1924 por Víctor Raúl Haya de la Torre. En su condición de partido político (Partido Aprista Peruano) llegó a ganar las elecciones presidenciales en los periodos de 1985-90 y 2006-11.

2 Las muestras de teatro del MOTIN se inician en 1974. Veintidós años después (1996) de haber recorrido diferentes regiones del Perú, se organiza la XVII Muestra en Huancayo. Evento que coincidió con la celebración de los 20 años de trabajo teatral del grupo Barricada. En dicho evento se alienta la necesidad de sistematizar los alcances de las muestras del MOTIN en un libro, logrando editarse al siguiente año el Libro de la muestra, que tuvo como integrantes del Consejo editorial a Lieve Delanoy, Sara Joffré, Manuel Luna, Ricardo Morante y María Reyna.

3 La primera participación de los grupos teatrales del centro del Perú - específicamente del departamento de Junín, departamento en el que geopolíticamente estarían circunscritos tanto Barricada como Expresión - en las muestras teatrales del MOTIN, se produjo en la VIII Muestra, organizada por 
la Universidad Nacional Daniel Alcides Carrión de Cerro de Pasco en el año de 1981. Los grupos que asistieron a dicha muestra fueron Semilla, que presentó la obra Del campo a la ciudad, dirigida por William Centeno, y el Taller de Teatro Bruno Terreros de Muquiyauyo, que presentó la obra Reforma, dirigida por Luis Suárez. Barricada asistió desde la XII Muestra, realizada en Puquio (Lucanas) en 1986. Expresión lo hizo desde la XIV Muestra en 1990, en Cajamarca.

${ }_{4}$ Cuando hablamos de teatro en singular y peruanos en plural, nos referirnos a un arte que, si bien se viene redefiniendo, conserva en el vocablo "teatro" rasgos homogeneizantes. Mientras que la diversidad de culturas, lenguas e identidades vivas en el Perú ha desbordado la idea de lo peruano como homogéneo. Además, con la expresión "teatro peruano(s)" queremos insistir en la diglosia lingüística, que da cuenta de una convivencia conflictiva y no armónica entre las diversas lenguas y culturas peruanas.

5 En el “Anexo 1. Cronología 1978-2000" del Informe final de la CVR, al verse los sucesos de 1995 sobre el tema de Derechos Humanos, se tiene el siguiente dato: "Un amplio informe elaborado por la Mesa Nacional sobre Desplazados en el Perú y la Coordinadora Nacional de Desplazados describe el drama de los 600,000 desplazados por la violencia política" (267) y se añade: "Más de 10,000 asháninkas [grupo étnico amazónico], agrupados en cincuenta comunidades indígenas, reclaman apoyo del gobierno para retornar a sus lugares de origen" (267).

6 Si bien el status de los "desplazados" en el Perú está definido y normado, su naturaleza desterritorializada sigue siendo conflictiva y vigente. La normatividad jurídica del desplazado se halla en condición de "archivo", en el Decreto Supremo Nº 073-93-PCM del 7 de octubre de 1993, que crea el Proyecto de Apoyo al Repoblamiento y Desarrollo de las Zonas de Emergencia y que fuera ratificado en el segundo gobierno de Alberto Fujimori mediante el Decreto Legislativo $\mathrm{N}^{\circ} 831$ del 9 de julio de 1996, que crea el Programa de Apoyo al Repoblamiento y Desarrollo de las Zonas de Emergencia-PAR. Además de la normatividad surgida a raíz de la divulgación del Informe Final de la Comisión de la Verdad, que se vio traducido a la Ley N ${ }^{\circ} 28223$, Ley sobre los Desplazamientos Internos (del 28 de abril de 2004) y su Reglamento respectivo (del 23 de febrero de 2005), este último conocido como el Decreto Supremo $\mathrm{N}^{\circ}$ 004-2005-MIMDES. Habría que sumar a todo este archivo jurídico la Ley $\mathrm{N}^{\circ} 28592$ (del 20 de julio del 2005) que crea el Plan Integral de Reparaciones-PIR.

7 Voz de tierra que llama forma parte de una tetralogía histórica. La particularidad de Voz de tierra que llama frente a las otras obras de la tetralogía es la de haber sido pensada como un unipersonal y pensada para ser representada por una actriz en específico: Digna Buitrón. Otras obras de Eduardo Valentín en la que Digna Buitrón tuvo un rol importante son: Preludio al verdadero del maestro (1989), La Mamacha de las Mercedes (1990), Vallejo profundo (1993), Cáceres, el estigma de la guerra (2001), Hacia la memoria desde la otra orilla (2004) y La revolución de los pingüinos (2006) y Kachkaniraqmi Micaela... Ni la muerte podrá separarnos (2012).

8 Voz de tierra que llama, de acuerdo al Libro de la Muestra, fue estrenada por el grupo en la XV Muestra en 1992, muestra organizada y llevada a cabo en el Cuzco. Como poemario la obra obtuvo el Premio Nacional Horacio en 1995. Fue antologada en la publicación Voces del interior, que realizara el estudioso Luis Ramos García en 2001 y vuelta a publicar el 2006 en la antología Nuestra dramaturgia, a la que nos remitiremos para precisar las citas textuales.

Junto a Barricada, en la Muestra de 1992 también participó el grupo Huancaíno Llaqtaymanta, dirigido por Edith Vargas, con la obra Allpallapaq, de corte campesino e igual tema que Voz de tierra que llama: el retorno de un campesino a sus tierras. No obstante de haber sido presentada en 1992, Voz de tierra que llama fue nuevamente representada en 1996 durante el desarrollo de la XVII Muestra desarrollada en la ciudad de Huancayo, muestra en la que el grupo de teatro Expresión estrenó Zoelia y Gronelio.

9 Sobre las migraciones del campo a la ciudad véase el valioso estudio de José Matos Mar, Desborde popular y crisis del Estado. Veinte años después.

${ }^{10}$ Las letras corresponden a los siguientes huaynos, según el orden de aparición. El primero es "Falsía" de Emilio Alanya. En la interpretación del más popular de los cantantes vernaculares de la sierra central peruana, Picaflor de los Andes, los últimos versos de la fuga dicen: "Ya me voy de esta tierra/ herido en el alma y el corazón. Mi vida ya no es vida en medio del valle de falsedades/ mi vida ya 
no es vida en medio de tantas injusticias/ Adiós, dime, amor mío; a tierras lejanas hoy me retiro/ Entre tantas injusticias, mi vida, no puedo sobrevivir". El segundo huayno-muliza es "Ayrampito" de Emilio Alanya y Tomás Palacios Fierro, interpretada por Flor Pucarina. En relación a Voz de tierra que llama, habría que tenerse en cuenta la tercera estrofa que dice: "Tantas mentiras, tantas traiciones/ me han perdido, ya no quisiera/ amar a nadie en la vida". La tercera canción es "Soy uno más en tu vida" de la tradición popular andina en cuyas letras se oyen las siguientes versos: "Unas palabras amorosas/y unas caricias allí me quedo/ aunque después mal me paguen, así es mi suerte conocida". No cabe duda que la canción que interpreta la séptima voz es una de las de más honda tragedia andina, tragedia entendida en la acepción nietzscheana. El título del huayno es "Maldita pasión", también del folklore tradicional andino. Los versos de la fuga dicen: "maldigo tu nombre, maldito cariño/ Maldigo el momento de haberte yo amado/ si es verdad que existe, justicia en el cielo/ por mi sufrimiento, irás al infierno". Canciones que uno puede oír en las siguientes direcciones electrónicas: "Falsía" en $<\mathrm{http} / /$ www.youtube.com/ watch?v=Fh6QRKy1H-A "Ayrampito" en http://www.youtube.com/watch?v=SyRc_Ua7PeI "Soy uno más en tu vida" en http://www.youtube.com/watch?v=cUfrBRUHTQY y "Maldita pasión" en http:// www.youtube.com/watch?v=ePU8_QTVECE>.

${ }^{11}$ El Santiago es una danza del Valle del Mantaro en honor al apóstol Santiago, Patrón de los animales. Se le representa todos los años desde el 24 de julio hasta la segunda semana de agosto. La música es interpretada con una tinya (tamborcillo) y una huacra (corneta de cuerno de toro). La representación de esta danza recrea el tiempo en el que los pastores a cargo del ganado bajan de las punas hacia el valle trayendo consigo flores especiales recogidas en las alturas o nevados para ofrecerlos al apóstol Santiago con el objetivo de ser favorecidos con la fertilidad del ganado. Entre las flores que ofrecen tenemos la Limalina, el Suncho, el Uwish, la Surasura, la Cuchichupa, la Calahualash, entre otras. La celebración de la fiesta se acompaña con hojas de coca, licor, víveres y música. Al día siguiente se procede a la marca del ganado.

${ }_{12}$ Para saber más sobre la utopía andina léanse los trabajos de Manuel Burga y Alberto Flores Galindo.

13 Dos estudios serios sobre la relación entre el "bestiario" andino y la violencia social son los de Gonzalo Portocarrero (1997) y Juan Ansión (1987). En ellos se dan a conocer "personajes" andinos como el condenado, que fueron retomados por la colectividad andina durante el tiempo del miedo.

${ }^{14}$ El baile del cual habla Valentín en Voz de tierra que llama debe asociarse a la llamada enfermedad del baile, al Taky Onkoy milenarista, el que fue objeto de estudio de Luis Millones.

\section{Obras citadas}

Ansión, Juan. Desde el rincón de los muertos. El pensamiento mítico en Ayacucho. Lima: Gredes, 1987. Impreso.

Ballón Aguirre, Enrique. Tradición oral peruana. Literaturas ancestrales y populares I. Lima: Fondo Editorial de la Pontificia Universidad Católica del Perú, 2006. Impreso.

Burga, Manuel. Nacimiento de una utopía. Muerte y resurrección de los incas. Lima: Instituto de Apoyo Agrario, 1988. Impreso.

Carlson, Marvin. The Haunted Stage: The Theatre as Memory Machine. Ann Arbor: U of Michigan P, 2003. Impreso.

Comisión de la Verdad y Reconciliación Nacional. Informe Final. Lima: CVR, 2003. 13-342. Internet. <http://www.cverdad.org.pe/ifinal/pdf/Tomo $\% 20$ 
-\%20ANEXOS/ANEXO\%201Cronologia\%201978-2000\%20ultima\%20 revision.pdf $>$.

Cornejo Polar, Antonio. Escribir en el aire. Ensayo sobre la heterogeneidad sociocultural en las literaturas andinas. Lima: Editorial Horizonte, 1994. Impreso.

Derrida, Jacques. Mal de archivo: una impresión freudiana. Trad. Paco Vidarte. Madrid: Trotta, 1997. Impreso.

Flores Galindo, Alberto. Buscando un inca: identidad y utopía en los Andes. La Habana: Casa de Las Américas, 1986. Impreso.

Haesbaert, Rogério. El mito de la desterritorialización: Del "fin de los territorios" a la multiterritorialidad. Buenos Aires: Siglo XXI Editores, 2011. Impreso.

Hutcheon, Linda. The Politics of Postmodernism. Nueva York: Routledge, 1989. Impreso.

Lyotard, Jean-Francois. La condición postmoderna: informe sobre el saber. Trad. Mariano Antolín Rato. Madrid: Cátedra, 2004. Impreso.

Manrique, Nelson. El tiempo del miedo. La violencia política en el Perú 1980-1996. Lima: Fondo Editorial del Congreso del Perú, 2002. Impreso.

Matos Mar, José. Desborde popular y crisis del Estado. Veinte años después. Lima: Fondo Editorial del Congreso de la República, 2004. Impreso.

Millones, Luis. Fuentes de estudio de la colonia, IV: Taqui Onkoy, de la enfermedad del canto a la epidemia. Santiago: Centro de Investigaciones Diego Barros, 2008. Impreso.

Portocarrero, Gonzalo, Isidro Valentín y Soraya Irigoyen. Sacaojos: crisis social y fantasmas coloniales. Lima: Tarea, 1991. Impreso.

Taylor, Diana. The Archive and the Repertoire: Performing Cultural Memory in the Americas. Durham: Duke UP, 2003. Impreso.

Valentín, Eduardo. Voz de tierra que llama. En Nuestra dramaturgia. Literatura del Valle del Mantaro. Décadas ochenta y noventa. Ed. Patricia Orihuela y Jorge Yangali. Huancayo: Grupo de Proyección Social Flor de Retama, 2006. 29-38. Impreso.

. Voz de tierra que llama. Voces del interior: nueva dramaturgia peruana.

Comp. Luis Ramos García. Lima: Instituto Nacional de Cultura, 2001. Impreso.

Varios. El libro de la Muestra de Teatro Peruano: Callao, Cajamarca I, Iquitos, Cerro de Pasco, Tacna, Lima, Cuzco I, Puquio, Andahuaylas, Cajamarca II, Cuzco II, Yurimaguas, Huancayo. Lima: Lluvia Editores, 1997. Impreso. Villagómez, Alberto. "La violencia política en el teatro peruano". Pacarina del Sur (México, D.F.) 3.11 (2012). Internet. <http://www.pacarinadelsur.com/ home/huellas-y-voces/243-la-violencia-politica-en-el-teatro-peruano>. 